\title{
Electric Fields in Energy and Process Engineering
}

\author{
Lars Zigan
}

Lehrstuhl für Technische Thermodynamik (LTT) and Erlangen Graduate School in Advanced Optical Technologies (SAOT), Friedrich-Alexander-Universität Erlangen-Nürnberg (FAU), D-91058 Erlangen, Germany; lars.zigan@fau.de; Tel.: +49-9131-8529770

Received: 5 July 2018; Accepted: 10 August 2018; Published: 27 August 2018

Abstract: This Editorial provides an introduction to and an overview of the special issue "Electric Fields in Energy and Process Engineering".

Keywords: plasma; ionic wind; heat and mass transfer; cooling; combustion; supersonic combustion; gasification; pollutant emission; water treatment; metrology

\section{Introduction}

Electric fields are applicable, in many engineering fields, to the improvement of heat and mass transfer, flow behavior as well as the chemical reactions involved in the technical process. Thus, the application of electric fields may increase the energy efficiency of the technical system and decrease the consumption of energy carriers. Furthermore, they are useful for reducing pollutant emissions and environmental contaminants [1]. Usually, a "plasma", which is characterized by high power density, is applied for process optimization, but "weak" electric fields, with low power density and without additional ionization, can also be utilized. The plasma can locally produce high temperatures and chemically active species, such as ozone $\left(\mathrm{O}_{3}\right)$, oxygen radical $(\mathrm{O})$, nitrogen radical $(\mathrm{N})$ and hydroxyl radical $(\mathrm{OH})$, as well as photons and charge carriers. In the field of energy and process engineering, plasmas are applied in the generation of electrosprays, for electrochemical reforming and for plasma gasification of coal, waste or biomass. Other emerging fields are plasma technologies for the treatment of water, surfaces and gases, including flue gases. Furthermore, plasmas are applicable to the control of the process of nanomaterial synthesis. In the field of metrology, non-invasive diagnostics based on plasmas are useful for the trace element analysis of the chemical composition of solids, liquids, or gases. Furthermore, the electromagnetic fields and electric fluid properties of involved materials are utilized for online process control and process optimization.

\section{Content of the Special Issue}

In the first review paper, an overview of electric field applications, relevant to energy and process engineering, is given [2]. The emphasis is on electric-field enhanced combustion as well as plasma-induced atomization and spray formation. These "electrosprays" are applicable for liquid fuel injection, relevant to micro-power generators, emulsion production and the production of monodisperse micro- and nano-particles. Environmental applications are based on the interaction of plasma and gaseous, liquid or solid material. This includes pollutant removal in the flue gas of technical burners, gas turbines, and IC engines, waste treatment and the gasification of coal and biomass. Plasma generation in liquid water allows for advanced oxidation processes, which are used for chemical processing or purification. Thus, plasma application can improve the chemical processing of industrial wastewater and drinking water. Especially, the utilization of plasma for minimizing organic pollutants has received increased attention. The removal of pollutants in flue gas [3] is mainly focused on volatile organic compounds (VOC) and nitric oxides $\left(\mathrm{NO}_{x}\right)$ as well as particulate matter 
(PM, for which electrostatic precipitators (ESP) [4] are applied). Furthermore, an overview, regarding the usage of plasma and electric fields for measuring process parameters in technical systems, which is deepened in a contributed article [5], is provided. A special topic is the usage of laser-based techniques, providing insights into plasma processes and electro-hydrodynamic effects [6]. Optical measurement techniques are also addressed in the articles contributed by Chien and Dunn-Rankin [7], Pang et al. [8] and in the review article by Leonov [9].

Mallach et al. [5] provide a detailed overview of different non-intrusive soft-field electromagnetic tomography systems. They are utilized for multiphase mixture and flow imaging in pipes for application in the process industry. These tomography systems are sensitive to the local contrasts of the electrical properties of the materials and are utilized for visualizing the spatial material distribution. This article describes the fundamental concepts, recent developments in sensor design, data acquisition and signal processing, with a focus on high-speed data acquisition and image reconstruction. Finally, impressive measurement applications, with fast variations in the spatial material distribution, are presented, including the mixing process of tap water and sodium chloride $(\mathrm{NaCl})$ and an oil-gas slug flow.

Jovicic et al. [10] present investigations on wastewater treatment using non-thermal atmospheric plasma for removing very low concentrations of perfluorinated compounds (PFC). These compounds are characterized by a high thermal and chemical stability. Thus, high temperatures (above $1000 \mathrm{~K}$ ) are necessary for their complete destruction, for which reason, especially, non-thermal atmospheric plasmas appear attractive. Effects of the treatment time, the plasma gas, the reactor size and the plasma nozzle length were studied in the framework of this investigation. It was verified that plasma treatment is an efficient method for the degradation of more than $50 \%$ of the initial PFC concentration in water samples within $200 \mathrm{~s}$. The final concentration of PFC depends on the conditions in the plasma reactor, indicating that high concentrations of plasma radicals are beneficial, and a reduction of the PFC concentration of up to $90 \%$ was possible.

Electric fields can be used to locally change the flow in a technical system and contribute to heat and mass transfer. For this purpose, a so-called "ionic wind" is produced, e.g., by corona discharge electrodes, which are also known as "ionic wind pumps". The released ions produce an electro-hydrodynamic effect, and the induced flow shows flow velocities in the range of a few meters per second [11]. The cooling of electronic elements, such as light emitting diodes (LEDs), is a relevant application of these ion wind generators and this is studied in the contribution of Qu et al. [12]. In this work, multiple corona electrodes were used to improve the flow rate of ionic wind for more efficient cooling. Effects on the resulting ionic wind velocity and LED temperature were studied for different parameters, including the number of needle electrodes, the distance between the electrodes and the polarity of the discharge. The maximum achieved temperature drop was $35.6 \mathrm{~K}$, compared to the initial temperature of $88.6^{\circ} \mathrm{C}$, in the case without ionic wind, indicating an efficient cooling performance.

Biomass gasification using non-thermal plasma (NTP) is a relatively new technique, and only few studies have been reported in the literature so far [2]. In [8], results of a collaborative project are presented, which was conducted by Siemens AG, Corporate Technology, Erlangen, Germany and two institutes at Friedrich-Alexander-Universität Erlangen-Nürnberg (Lehrstuhl für Technische Thermodynamik, Erlangen, Germany; and Lehrstuhl für Energieverfahrenstechnik, Nürnberg, Germany) in the framework of "Campus Future Energy Systems (Campus FES)". In this study, a gliding arc plasma was used for initializing the gasification reactions by the generation of additional free radicals. The plasma gasification of wood and charcoal powder was studied in a drop tube reactor. Water steam was used as a gasification agent and plasma medium. NTP-assisted gasification leads to enhanced hydrogen production due to water dissociation, and the production of carbon monoxide (CO), carbon dioxide $\left(\mathrm{CO}_{2}\right)$ and methane $\left(\mathrm{CH}_{4}\right)$ increased as well. This leads to an increased carbon conversion rate, which is about $10 \%$ higher for wood powder using NTP-assisted gasification compared to pure thermal gasification. For charcoal powder, the increase in the carbon conversion rate is higher than $3 \%$. 
One main field of this special issue is electric-field enhanced combustion, as burners are widely used for heat generation in energy and process engineering. The production of nano-particles by (spray) flame synthesis, and the control of these particle formation processes by electric fields [13], is a special application, addressed in [2]. Basically, the interactions between electric fields and flames are based on the existence of charge carriers produced by the chemi-ionization in the reaction zone of hydrocarbon flames [14]. The generated ionic wind can be used for flame stabilization and the minimization of pollutant emissions, such as soot, $\mathrm{CO}$ or nitric oxides $\left(\mathrm{NO}, \mathrm{NO}_{2}\right)$. Furthermore, thermo-acoustic oscillations occurring in the combustion chamber can be suppressed using electric fields [15-17] in order to avoid potential damage to the combustor.

Recent studies focus on the flame-wall interaction [18], which can be affected by using ionic wind. This is useful for controlling the heat transfer from the flame to the wall and for avoiding flame quench [19]. Fundamental studies on that topic are reported in [7]. Optical diagnostics were applied, including a forward-looking infrared (FLIR) camera and Schlieren visualization for the examination of the heat flux of flames over an impinging plate. The applied electric fields are applicable for controlling the heat flux distribution through the ion-driven wind. This demonstrates a high potential for "electric field focusing of heat from flames" [7] with manifold applications in thermal management.

Fundamental work on plasma-assisted supersonic combustion, which is realized in scramjet engines, is reviewed in [9], with a special focus on mixing enhancement as well as ignition and flame stabilization. The main idea of plasma application is its ability to initialize and support chemical reactions, especially at low gas temperature. This could contribute to a stable operation of the engines in a wider range of flight conditions as well as to a reduction in total pressure losses. Besides numerical simulation, manifold experiments using optical diagnostics were performed for the visualization of the discharge, the flow and mixing field, as well as the combustion. These results show a progress in understanding the involved mechanisms of plasma-flow interactions, leading to a significant enhancement of the performance of supersonic combustors.

\section{Conclusions and Outlook}

The contributed articles in this special issue discuss a wide variety of potential electric field applications, relevant to energy and process engineering. However, for most systems, there are still many challenges that must be solved in order to meet industrial requirements. Energy efficiency is the main constraint in the application of plasma technologies at the industrial scale. Nevertheless, fundamental studies on these processes are worthwhile, as the control of these discharges can efficiently exploit the plasma's chemical reactivity. For the optimization of these systems, a deep understanding of the fundamental plasma-material interactions is necessary. This requires both novel computational strategies and improved diagnostic techniques. Newly developed optical high-speed techniques, especially laser-based diagnostics, will provide deepened insights into plasma processes in fundamental studies. Furthermore, electric field-based measurement techniques for on-line process monitoring deliver instant feedback on process efficiency. They provide ways for the control and optimization of these processes. Hence, these techniques are beneficial for waste reduction and improving the overall energy efficiency and performance of the systems.

Funding: This research received no external funding.

Acknowledgments: The guest editor would like to thank the authors for submitting their excellent contributions to this special issue. Furthermore, he thanks the reviewers for evaluating the manuscripts and providing helpful suggestions. A special thank you goes to the editors and the MDPI team for their outstanding management of this special issue.

Conflicts of Interest: The author declares no conflict of interest. 


\section{References}

1. Reece Roth, J. Principles. In Industrial Plasma Engineering; CRC Press: Boca Raton, FL, USA, 1995; Volume 1.

2. Zigan, L. Overview of Electric Field Applications in Energy and Process Engineering. Energies 2018, 11, 1361. [CrossRef]

3. Hammer, T. Atmospheric Pressure Plasma Application for Pollution Control in Industrial Processes. Contrib. Plasma Phys. 2014, 54, 187-201. [CrossRef]

4. Poškas, R.; Sirvydas, A.; Poškas, P.; Jouhara, H.; Striūgas, N.; Pedišius, N.; Valinčius, V. Investigation of warm gas clean-up of biofuel flue and producer gas using electrostatic precipitator. Energy 2018, 143, 943-949. [CrossRef]

5. Mallach, M.; Gevers, M.; Gebhardt, P.; Musch, T. Fast and Precise Soft-Field Electromagnetic Tomography Systems for Multiphase Flow Imaging. Energies 2018, 11, 1199. [CrossRef]

6. Kuhl, J.; Seeger, T.; Zigan, L.; Will, S.; Leipertz, A. On the effect of ionic wind on structure and temperature of laminar premixed flames influenced by electric fields. Combust. Flame 2017, 176, 391-399. [CrossRef]

7. Chien, Y.-C.; Dunn-Rankin, D. Electric Field Induced Changes of a Diffusion Flame and Heat Transfer near an Impinging Surface. Energies 2018, 11, 1235. [CrossRef]

8. Pang, Y.; Bahr, L.; Fendt, P.; Zigan, L.; Will, S.; Hammer, T.; Baldauf, M.; Fleck, R.; Müller, D.; Karl, J. Plasma-assisted biomass gasification with focus on carbon conversion and reaction kinetics compared to thermal gasification. Energies 2018, 11, 1302. [CrossRef]

9. Leonov, S.B. Electrically-driven supersonic combustion. Energies 2018, 11, 1733. [CrossRef]

10. Jovicic, V.; Khan, M.J.; Zbogar-Rasic, A.; Fedorova, N.; Poser, A.; Swoboda, P.; Delgado, A. Degradation of low concentrated perfluorinated compounds (PFCS) from water samples using non-thermal atmospheric plasma (NTAP). Energies 2018, 11, 1290. [CrossRef]

11. Weinberg, F.; Carleton, F.; Kara, D.; Xavier, A.; Dunn-Rankin, D.; Rickard, M. Inducing gas flow and swirl in tubes using ionic wind from corona discharges. Exp. Fluids 2006, 40, 231-237. [CrossRef]

12. Qu, J.; Kong, L.; Zhang, J. Experimental investigation on flow and heat transfer characteristics of a needle-cylinder type ionic wind generator for LED cooling. Energies 2018, 11, 1149. [CrossRef]

13. Kammler, H.K.; Pratsinis, S.E. Electrically-assisted flame aerosol synthesis of fumed silica at high production rates. Chem. Eng. Process. Process Intensif. 2000, 39, 219-227. [CrossRef]

14. Lawton, J.; Weinberg, F.J. Electrical Aspects of Combustion; Clarendon Press: Oxford, UK, 1969.

15. Kuhl, J.; Jovicic, G.; Zigan, L.; Will, S.; Leipertz, A. Influence of electric fields on premixed laminar flames: Visualization of perturbations and potential for suppression of thermoacoustic oscillations. Proc. Combust. Inst. 2015, 35, 3521-3528. [CrossRef]

16. Lacoste, D.A.; Xiong, Y.; Moeck, J.P.; Chung, S.H.; Roberts, W.L.; Cha, M.S. Transfer functions of laminar premixed flames subjected to forcing by acoustic waves, AC electric fields, and non-thermal plasma discharges. Proc. Combust. Inst. 2017, 36, 4183-4192. [CrossRef]

17. Volkov, E.N.; Kornilov, V.N.; de Goey, L.P.H. Experimental evaluation of DC electric field effect on the thermoacoustic behaviour of flat premixed flames. Proc. Combust. Inst. 2013, 34, 955-962. [CrossRef]

18. Chien, Y.-C.; Escofet-Martin, D.; Dunn-Rankin, D. CO emission from an impinging non-premixed flame. Combust. Flame 2016, 174, 16-24. [CrossRef] [PubMed]

19. Weinberg, F.J.; Dunn-Rankin, D.; Carleton, F.B.; Karnani, S.; Markides, C.; Zhai, M. Electrical aspects of flame quenching. Proc. Combust. Inst. 2013, 34, 3295-3301. [CrossRef]

(C) 2018 by the author. Licensee MDPI, Basel, Switzerland. This article is an open access article distributed under the terms and conditions of the Creative Commons Attribution (CC BY) license (http://creativecommons.org/licenses/by/4.0/). 